\title{
Diagnostyka ultrasonograficzna i wewnątrznaczyniowe udrożnienie tętnicy po embolizacii tętniaka mózgu powikłanej zakrzepem tętnicy szyjnej wewnętrznej
}

\section{Sonographic diagnosis and endovascular recanalization of the internal carotid artery in a patient with carotid thromboembolism following coiling of cerebral aneurysm}

Grzegorz Turek', Jan Kochanowicz', Andrzej Lewszuk², Robert Rutkowski', Tomasz kysoń', Kazimierz Kordecki², Zenon Mariak'

1 Klinika Neurochirurgii, Uniwersytet Medyczny w Białymstoku

2Zakład Radiologii, Uniwersytet Medyczny w Białymstoku

Neurologia i Neurochirurgia Polska 2011; 45, 3: 286-291

\section{Streszczenie}

Powikłania zatorowo-zakrzepowe po leczeniu wewnątrznaczyniowym tętniaków mózgu stanowią zagrożenie życia, ale wciąż leczone są najczęściej zachowawczo. Rzadko stosowaną alternatywą jest interwencja wewnątrznaczyniowa, której skuteczność ściśle zależy od czasu jej przeprowadzenia. Niniejszy opis przypadku podkreśla użyteczność przezczaszkowej ultrasonografii z kolorowym obrazowaniem przepływu krwi w szybkim rozpoznaniu różnicowym oraz skuteczność natychmiastowej interwencji drogą wewnątrznaczyniową.

U 50-letniej chorej po zabiegu ponownej embolizacji tętniaka tętnicy szyjnej wewnętrznej doszło do wystąpienia objawów neurologicznych. Badanie dopplerowskie wykazało zmniejszenie prędkości przepływu krwi w tętnicy środkowej mózgu, a angiografia - prawie całkowitą niedrożność tętnicy szyjnej wewnętrznej. Podano heparynę, wykonano pilną trombektomię drogą wewnątrznaczyniową i założono do naczynia stent, uzyskując ustąpienie objawów.

Przezczaszkowa ultrasonografia dopplerowska z kolorowym obrazowaniem przepływu krwi pozwala szybko rozpoznać powikłania po embolizacji tętniaków mózgu związane z zaburzeniem przepływu krwi w naczyniach wewnątrzczaszkowych. Umożliwia to szybką i skuteczną interwencję wewnątrznaczyniową w przypadku powikłań zatorowo-zakrzepowych.

Słowa kluczowe: tętniak wewnątrzczaszkowy, embolizacja wewnątrznaczyniowa, powikłania zakrzepowe, przezczaszkowa ultrasonografia dopplerowska $\mathrm{z}$ kolorowym obrazowaniem przepływu krwi.

\begin{abstract}
Thromboembolism after brain aneurysm embolization involves high morbidity/mortality and its conservative treatment is still a standard policy. We report the practical utility of transcranial colour-coded Doppler sonography (TCCS) in the early diagnosis and effectiveness of prompt intravascular intervention in the treatment of this condition.

A 50-year-old woman developed acute neurological deficit after intravascular re-embolization of a brain aneurysm. Severely decreased blood flow velocity in the middle cerebral artery was revealed with TCCS and angiography confirmed nearly complete occlusion of the carotid artery. After heparin administration, intravascular thrombectomy was performed at the same session with implantation of a stent. The symptoms faded away within hours and the patient recovered fully.

Prompt intravascular intervention could be a valuable and efficient alternative in the treatment of thromboembolism after embolization of cerebral aneurysm. TCCS enables early differential diagnosis of this potentially devastating sequel.
\end{abstract}

Key words: intracranial aneurysm, detachable coils, thromboembolism, transcranial color-coded Doppler sonography.

Adres do korespondencii: Grzegorz Turek, Klinika Neurochirurgii, Uniwersytet Medyczny w Białymstoku, ul. Marii Skłodowskiej-Curie 24a, 15-276 Białystok, Polska, tel. +48 6964547 53, faks +48 8574559 22; e-mail: turekgrzegorz@vp.pl

Prace otrzymano: 5.07.2010; przyięto do druku: 4.01.2011 


\section{Wstęp}

Embolizacja jest coraz częściej wybieraną metodą leczenia tętniaków wewnątrzczaszkowych $[1,2]$. Jednakże zarówno skuteczność, jak i bezpieczeństwo tej metody podlegaja $\mathrm{w}$ dalszym ciagu oszacowaniom i sa przedmiotem dyskusji [3-8]. Pomimo postępu w technice embolizacji i coraz większej wprawy operatorów, wciąż zdarzają się powikłania, których częstość ocenia się w różnych doniesieniach na 10-19\% $[9,10]$. Do głównych powikłań embolizacji, oprócz pęknięcia tętniaka w trakcie zabiegu (od 2,9 do 8,8\%), sprowokowania skurczu naczyniowego wprowadzonym cewnikiem i migracji spirali $(0,5-2,9 \%)$, należą powikłania zakrzepowo-zatorowe, których częstość różni autorzy oceniają na 2,5-28\% [8,10-12]. Duże ryzyko związane z zaistnieniem powikłań zakrzepowych nakazuje możliwie szybką ich diagnostykę oraz energiczne i skuteczne postępowanie. Niniejsze doniesienie podkreśla rolę przezczaszkowej ultrasonografii dopplerowskiej z kolorowym obrazowaniem przepływu krwi, która daje

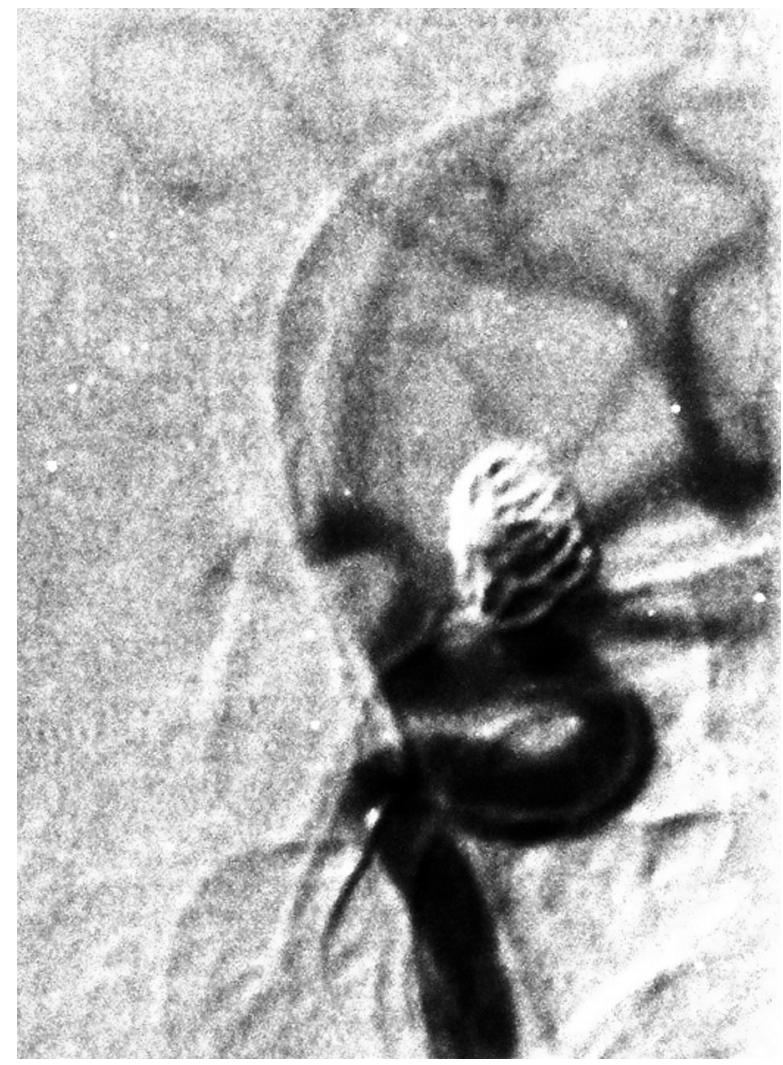

Ryc. 1. Angiografia cyfrowa tętnicy szyjnej wewnętrznej lewej. Niecałkowite wypetnienie tętniaka spiralq embolizacyjnq

Fig. 1. Digital subtraction angiography (DSA) of the left internal carotid artery. Incomplete embolization of the aneurysm szansę na wykrycie zaburzenia przepływu w naczyniach, nieraz nawet przed wystąpieniem objawów klinicznych.

Większość autorów podaje, że w przypadku stwierdzenia powikłań zatorowo-zakrzepowych stosowano postępowanie „zachowawcze”, które ograniczało się do podania dożylnego (lub nieraz dotętniczego) aktywatorów plazminogenu, urokinazy lub leków przeciwpłytkowych [13]. Raportowana śmiertelność na skutek tych powikłań wynosiła jednakże ok. 14-30\%, co nakazuje poszukiwanie alternatywnych, skuteczniejszych sposobów interwencji $[8,14]$. Postęp technologiczny umożliwia obecnie dotarcie do miejsca niedrożności drogą przeznaczyniową oraz usunięcie zakrzepu i przywrócenie przepływu krwi. Takie postępowanie nie jest jeszcze standardowo wykonywanym zabiegiem, dlatego autorzy chca przedstawić sposób, w jaki udało im się, dzięki szybkiej diagnostyce i natychmiastowej interwencji, skutecznie przywrócić prawidłowy przepływ krwi w tętnicy środkowej mózgu i uzyskać bardzo dobry efekt kliniczny.

\section{Opis przypadku}

U 50-letniej pacjentki w październiku 2008 r. wykonano embolizację tętniaka w odcinku C2 tętnicy szyjnej wewnętrznej. Tętniak zamknięto kompletnie i bez powikłań, przy użyciu trzech spiral. W maju 2009 r. chora zgłosiła się ponownie do kliniki w celu planowej kontroli skuteczności embolizacji tętniaka. Badanie angiograficzne wykazało agregację spiral w obrębie kopuły tętniaka, z odtworzeniem przepływu w okolicy jego szyjki (ryc. 1.). Pacjentka nie wyraziła wówczas zgody na uzupełniającą embolizację, którą podjęto dopiero na początku lutego $2010 \mathrm{r}$.

Przy przyjęciu chora była w stanie ogólnym dobrym, bez objawów ogniskowych ani deficytów neuropsychologicznych. Po przygotowaniu farmakologicznym (klopidogrel doustnie w dawce $75 \mathrm{mg}$ raz na dobę przez 5 dni) przeprowadzono embolizację w znieczuleniu ogólnym, w godzinach rannych. Użyto cewnika prowadzącego Casasco 6F oraz mikrocewnika Casco 10+, przez który bez problemów technicznych umieszczono w obrębie tętniaka dodatkowe 4 spirale platynowe odczepiane mechanicznie. Stwierdzono, że zawój ostatniej z umieszczonych spirali uwypuklał się do światła naczynia. Po przeanalizowaniu sytuacji zdecydowano się na pozostawienie tej spirali pod osłoną heparyny drobnocząsteczkowej, ponieważ w kontrolnej angiografii nie stwierdzono zaburzeń przepływu krwi w kierunku gałęzi obwodowych tętnicy szyjnej, a po ewentualnym usunięciu 


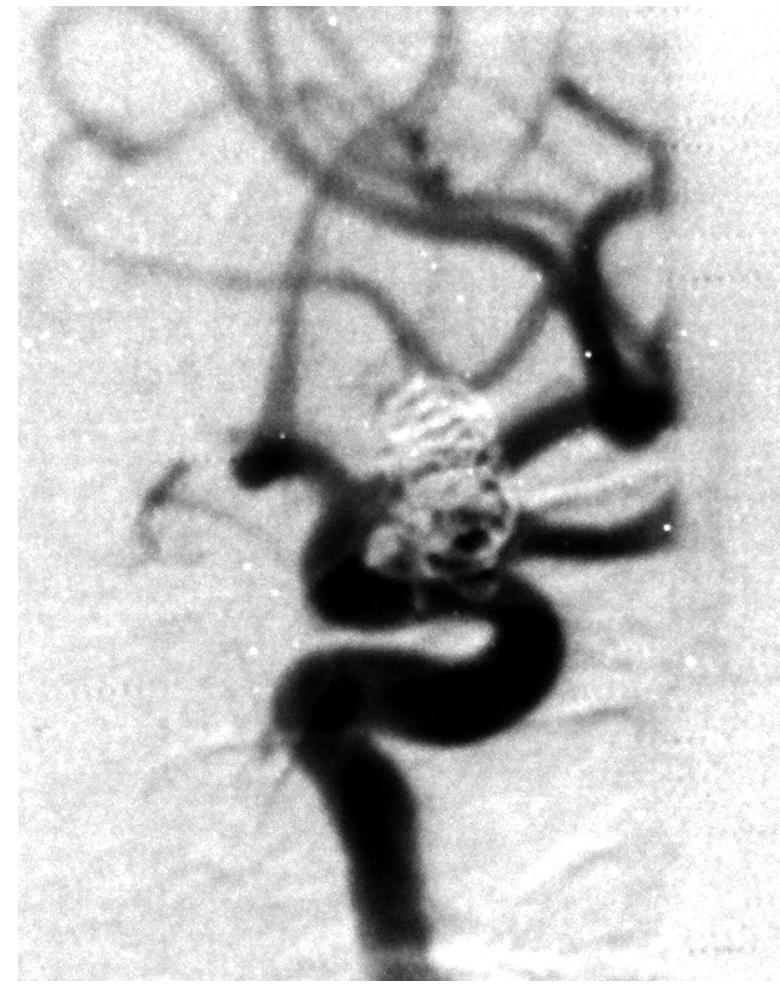

Ryc. 2. Stan bezpośrednio po embolizacii uzupełniającej tętniaka. Fragment spirali embolizacyinej uwypukla się do światta tętnicy szyjnej wewnętrznej

Fig. 2. DSA after complementary embolization of the aneurysm. Last coil partially protrudes to the lumen of the internal carotid artery

spirali embolizacja tętniaka nie byłaby całkowita (ryc. 2.). Chora po zakończeniu znieczulenia ogólnego była w stanie ogólnym dobrym, w pełnym logicznym kontakcie, bez deficytów neurologicznych. Jednakże po ok. 20 min pojawiły się niedowład połowiczy prawostronny oraz afazja mieszana, które szybko narastały.

Wykonana przezczaszkowa ultrasonografia dopplerowska z kolorowym obrazowaniem przepływu (transcranial color-coded sonography - TCCS) wykazała znaczne zmniejszenie prędkości skurczowej przepływu krwi w lewej tętnicy środkowej mózgu. Prędkość ta wynosiła $27 \mathrm{~cm} / \mathrm{s}$ (norma: $54-166 \mathrm{~cm} / \mathrm{s}$ ), co wykluczało obecność skurczu naczyń, natomiast sugerowało znaczne upośledzenie przepływu na tle częściowej niedrożności tętnicy. W związku z tym podano leki przeciwzakrzepowe w dużych dawkach (heparyna drobnocząsteczkowa $0,6 \mathrm{ml}$ podskórnie oraz klopidogrel $\mathrm{w}$ dawce $300 \mathrm{mg}$ doustnie). Jednocześnie w trybie pilnym powtórzono angiografię mózgową, stwierdzając krytyczne upośledzenie drożności tętnicy szyjnej wewnętrznej lewej od poziomu tętniaka, a także słabe wykontrastowanie

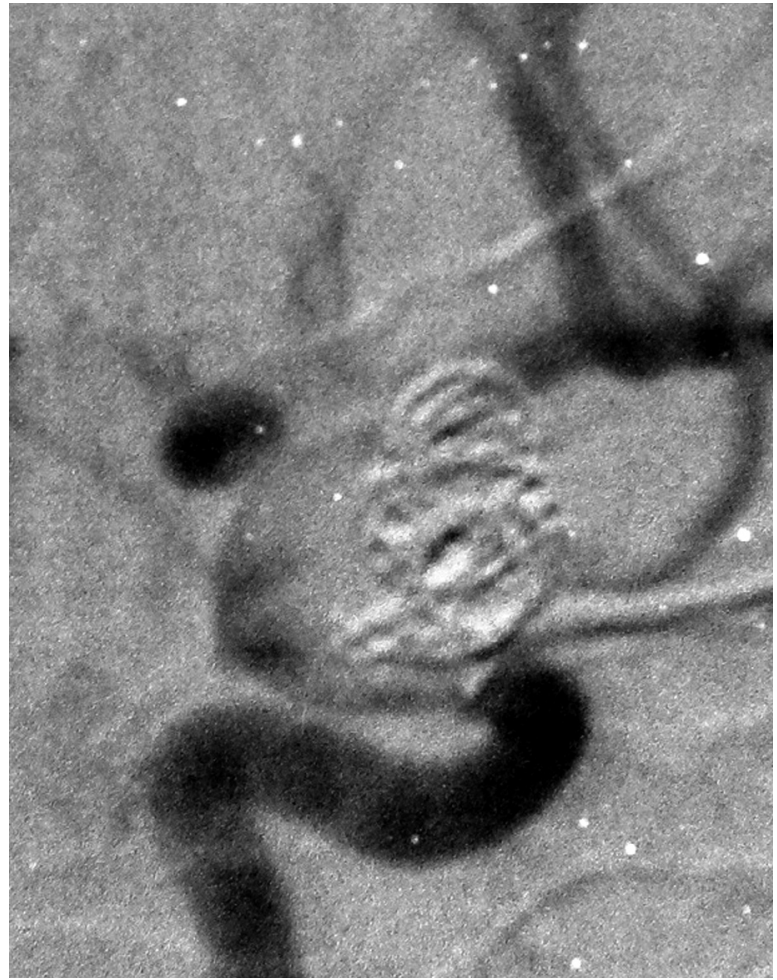

Ryc. 3. Badanie angiograficzne po ok. 40 min od ponownej embolizacii tętniaka wskazuiqace na obecność zakrzepu, który w stopniu krytycznym upośledza przepływ w tętnicy szyjnej i jei głównych gałęziach

Fig. 3. DSA of the internal carotid artery performed 40 minutes after the complementary coiling of the aneurysm demonstrates critically narrowed lumen of the vessel due to its thromboembolism

tętnicy środkowej mózgu i brak wykontrastowania tętnicy przedniej mózgu (ryc. 3.).

$\mathrm{Z}$ uwagi na pogarszanie się stanu chorej, duży niedowład i narastające zaburzenia świadomości podjęto decyzję o wykonaniu zabiegu udrożnienia tętnic wewnątrzczaszkowych drogą wewnątrznaczyniową. Przed zabiegiem podano 5 tys. jednostek heparyny we wlewie kroplowym. $\mathrm{Na}$ pierwszym etapie zabiegu do dystalnego odcinka tętnicy szyjnej wprowadzono mikroprowadnik typu Steel 0,012 (Balt), następnie po nim - mikrocewnik typu Vasco +21 . Przez mikrocewnik wprowadzono urządzenie do usuwania skrzepliny typu Catch (zestaw do trombembolektomii, Balt). Jest to mikrocewnik, w którym znajduje się mikroprowadnik z zamontowanym na końcu składanym koszykiem wykonanym z cienkich drucików. Po przeprowadzeniu mikrocewnika poza widoczną skrzeplinę koszyk rozkłada się, po czym urządzenie jest usuwane wraz z zawartą w koszyku skrzepliną. Po wykonaniu tych czynności u pacjentki uzyskano przepływ krwi przez tętnicę szyjną oraz środkową mózgu, natomiast nadal nie było zakontrastowania tętnicy mózgu przedniej. 

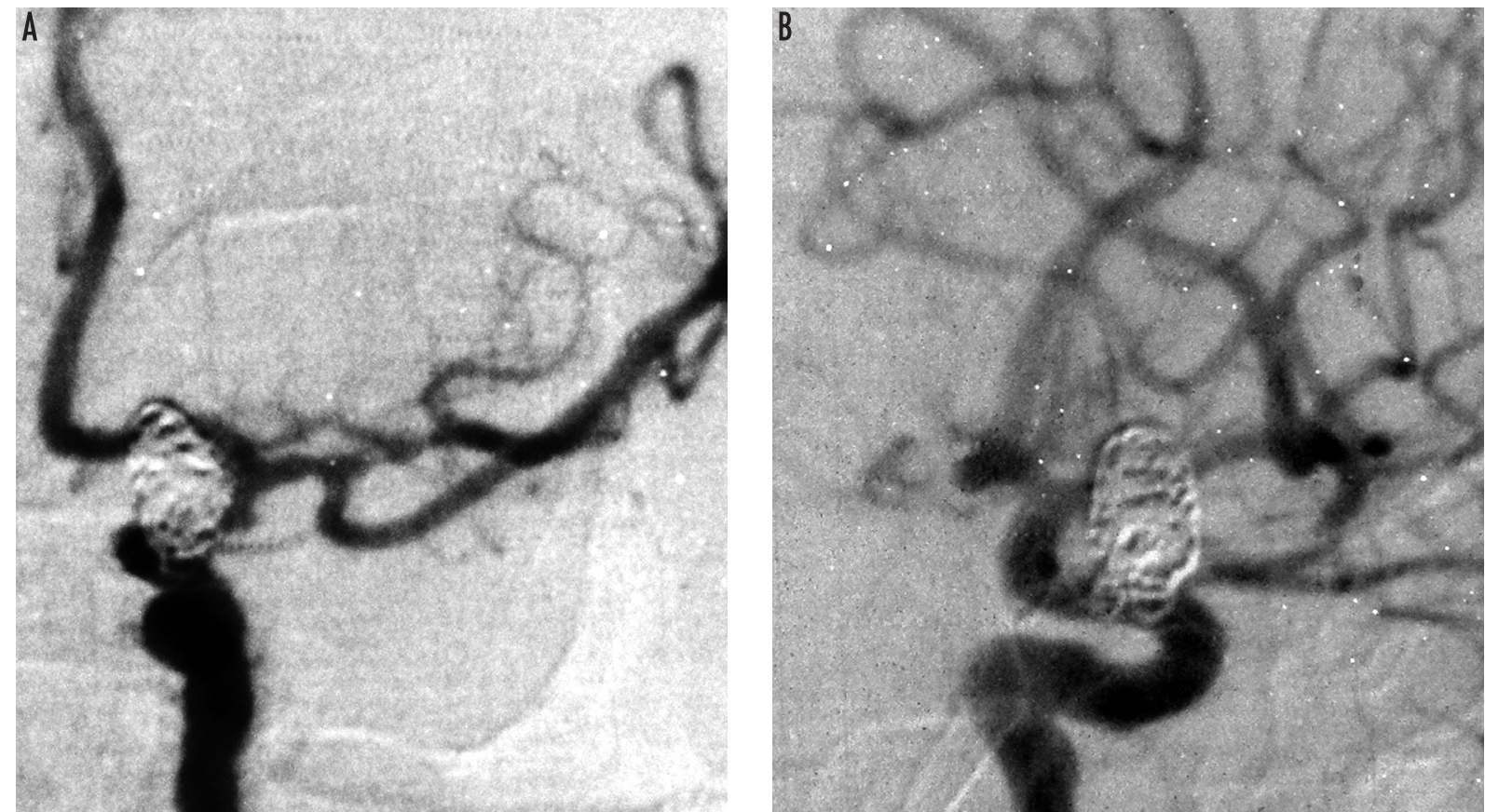

Ryc. 4. Badanie angiograficzne w projekcii przednio-tylnej i bocznej bezpośrednio po wykonaniu trombektomii i wszzzepieniu stentu. Widoczny prawidłowy przepływ środka kontrastowego przez odgałęzienia tętnicy szyinej wewnętrznej

Fig. 4. Antero-posterior and lateral projection of DSA directly after thrombectomy and implantation of a stent demonstrates restoration of blood flow in the internal carotid artery and its branches

Ze względu na ryzyko ponownego powstania materiału zakrzepowego na uwypuklonych pętlach spiral, a także z powodu niepewnego wyniku trombektomii podjęto decyzję o wszczepieniu stentu mózgowego na wysokości szyi tętniaka (ryc. 4.). W tym celu po mikroprowadniku typu SOR 0,009 (Balt) wprowadzono mikrocewnik typu Vasco +21 , a przez mikrocewnik do tętnicy szyjnej wewnętrznej na wysokości szyi tętniaka - stent nitynolowy samorozprężalny typu Leo+ o wymiarze $4,5 \times 20 \mathrm{~mm}$ (Balt) [15]. W wyniku tego zabiegu stwierdzono powrót zupełnie prawidłowego przepływu krwi w tętnicy szyjnej wewnętrznej, w tętnicy środkowej mózgu i w tętnicy przedniej mózgu. Zakres i nasilenie deficytów utrzymywały się jednakże do końca dnia bez zmian w stosunku do stanu sprzed zabiegu. Co jednak istotne - w badaniu dopplerowskim stwierdzono zdecydowaną poprawę przepływu krwi przez tętnicę mózgu środkową lewą: prędkość krwi wynosiła już $104 \mathrm{~cm} / \mathrm{s}$, a zatem powróciła do normy.

Po zabiegu kontynuowano leczenie przeciwzakrzepowe (heparyna drobnocząsteczkowa $\mathrm{w}$ dawce $0,6 \mathrm{ml}$ podskórnie raz na dobę), podano dożylnie roztwór Ringera, 0,9-procentowy $\mathrm{NaCl}$ oraz HAES w łącznej ilości $2500 \mathrm{ml} /$ dobę, osiągając wartość hematokrytu w gra- nicach 30\%, stężenie hemoglobiny we krwi $10 \mathrm{~g} / \mathrm{dl}$ i ośrodkowe ciśnienie żylne $>10 \mathrm{mmHg}$. Kontynuowano wlew nimodypiny do żyły podobojczykowej. Dopiero w godzinach wieczornych zaczęła ustępować afazja i nieco zmniejszył się niedowład. Następnego dnia pacjentka była w znacznie lepszym stanie, nawiązywała logiczny kontakt, spełniała polecenia, chociaż niedowład wciąż się utrzymywał. Badanie dopplerowskie potwierdziło prawidłowe wartości prędkości przepływu krwi przez naczynia mózgowe. W kolejnych dniach stan chorej poprawiał się i po 10 dniach została wypisana do domu bez afazji i niedowładu. Prędkość skurczowa krwi w tętnicy środkowej mózgu wynosiła $118 \mathrm{~cm} / \mathrm{s}$.

\section{Omówienie}

Jak wynika z doniesień na temat leczenia tętniaków mózgu za pomocą embolizacji, incydenty zatorowo-zakrzepowe są jednym z częstszych powikłań tych zabiegów $[8,10,11,14]$. Park i wsp. w doniesieniu opartym na materiale 210 pacjentów stwierdzili, że powikłania tego typu stanowią $60 \%$ wszystkich powikłań po embolizacji i występują najczęściej w dwóch pierwszych dobach po 
zabiegu [8]. Warto zauważyć, że powikłania te przy embolizacji tętniaków wewnątrzczaszkowych znacznie częściej występują u kobiet, co potwierdzają również Bradac i wsp., w których obszernym materiale ponad 500 embolizacji zatorowość wystąpiła u 36 chorych, z czego aż $80 \%$ stanowity kobiety [16]. Opisana pacjentka nie przyjmowała hormonalnej terapii zastępczej, która zwiększa ryzyko powikłań zakrzepowych.

Należy podkreślić, o czym już wspomniano we wstępie, że tromboembolizm jako powikłanie leczenia wewnątrznaczyniowego tętniaka mózgu to powikłanie wyjątkowo niebezpieczne. Jak podają Park i wsp., współistnieje ono często $\mathrm{z}$ innymi powikłaniami występującymi po embolizacji i jest przyczyną połowy zejść śmiertelnych związanych z zabiegami embolizacji tętniaków. Z powyższego materiału wynika, że wystąpienie tromboembolii wiąże się z odsetkiem poważnych powikłań wynoszącym 45\% oraz z 30-procentową śmiertelnością. Dlatego autorzy ci proponują, aby po zakończeniu embolizacji profilaktycznie podawać dożylnie eptifibatid, który jest syntetycznym heptapeptydem o dużym powinowactwie do receptora glikoproteinowego IIb/IIIa.

Zakrzepica dużych tętnic mózgowych zagraża udarem mózgu, który dodatkowo może pogorszyć stan pacjenta już obciążonego skutkami krwotoku podpajęczynówkowego. Czas to parametr krytyczny i w tej sytuacji trudno już nawet mówić o „złotej godzinie”, raczej należy liczyć minuty od zamknięcia naczynia do jego efektywnego udrożnienia. Elementem kluczowym jest (oprócz intensywnego nadzoru) jak najszybsza diagnostyka, przy czym o rozpoznaniu rozstrzyga ostatecznie angiografia mózgowa. Autorzy chcieliby jednak również wskazać na istotną rolę przezczaszkowej ultrasonografii dopplerowskiej z kolorowym obrazowaniem przepływu, która powinna być wykonywana rutynowo u chorych po tych zabiegach. W opisywanym przypadku badanie wykonane kilkanaście minut po zabiegu embolizacji wskazywało na znaczne zmniejszenie prędkości przepływu w tętnicy środkowej mózgu, co od razu sugerowało obecność zaburzeń drożności tętnicy szyjnej. Należy dodać, że badanie to pozwala już na wstępie zróżnicować zakrzepicę naczynia od jego skurczu (który często nasila się po zabiegu embolizacji), ponieważ w przypadku skurczu obserwuje się znaczny wzrost prędkości przepływu krwi $[16,17]$. Szybko ustalone rozpoznanie pozwoliło w opisywanym przypadku na niezwłoczną decyzję o wykonaniu badania angiograficznego i podjęcie skutecznego leczenia z zastosowaniem interwencji wewnątrznaczyniowej.
W podsumowaniu autorzy stwierdzają, że powikłania zatorowo-zakrzepowe po embolizacji tętniaków mózgu mogą być skutecznie leczone droga wewnątrznaczyniową. Przezczaszkowa ultrasonografia dopplerowska z kolorowym obrazowaniem przepływu pozwala wcześnie wykryć powikłania zatorowo-zakrzepowe po embolizacji tętniaków mózgu i ocenić skuteczność leczenia.

\section{Oświadczenie}

Praca została wsparta przez Ministerstwo Nauki i Szkolnictwa Wyższego grantem N 403040 32/2157. Autorzy zgłaszają brak konfliktu interesów.

\section{Piśmiennictwo}

1. Molyneux A., Kerr R., Stratton I. i wsp. International Subarachnoid Aneurysm Trial (ISAT) Collaborative Group. International Subarachnoid Aneurysm Trial (ISAT) of neurosurgical clipping versus endovascular coiling in 2143 patients with ruptured intracranial aneurysms: a randomised trial. Lancet 2002; 360: 1267-1274.

2. Koebbe C.J., Veznedaroglu E., Jabbour P. i wsp. Endovascular management of intracranial aneurysms: current experience and future advances. Neurosurgery 2006; 59: 93-102.

3. Raymond J., Roy D. Safety and efficacy of endovascular treatment of acutely ruptured aneurysms. Neurosurgery 1997; 41: 1235-1245.

4. Taha M.M., Nakahara I., Higashi T. i wsp. Endovascular embolization vs. surgical clipping in treatment of cerebral aneurysms: morbidity and mortality with short-term outcome. Surg Neurol 2006; 66: 277-284.

5. Henkes H., Fischer S., Weber W. i wsp. Endovascular coil occlusion of 1811 intracranial aneurysms: early angiographic and clinical results. Neurosurgery 2004; 54: 268-280.

6. Brilstra E.H., Rinkel G.J., van der Graaf Y. i wsp. Treatment of intracranial aneurysms by embolization with coils: a systematic review. Stroke 1999; 30: 470-476.

7. Czepko R. Współczesne metody i wyniki leczenia tętniaków mózgu. Przegl Lek 2003; 60: 740-743.

8. Park H.K., Horowitz M., Jungreis C. i wsp. Periprocedural morbidity and mortality associated with endovascular treatment of intracranial aneurysms. AJNR Am J Neuroradiol 2005; 26 : 506-514.

9. Proust F., Martinaud O., Gérardin E. i wsp. Quality of life and brain damage after microsurgical clip occlusion or endovascular coil embolization for ruptured anterior communicating artery aneurysms: neuropsychological assessment. J Neurosurg 2009; 110: 19-29.

10. Deng J., Zhao Z., Gao G. Periprocedural complications associated with endovascular embolization of intracranial ruptured aneurysms with matrix coils. Singapore Med J 2007; 48: 429-433. 
11. Pelz D.M., Lownie S.P., Fox A.J. Thromboembolic events associated with the treatment of cerebral aneurysms with Guglielmi detachable coils. AJNR Am J Neuroradiol 1998; 19: 1541-1547.

12. Mariak Z., Kochanowicz J., Kordecki K. i wsp. Chirurgiczne usunięcie spirali embolizacyjnej przemieszczonej do tętnicy środkowej mózgu. Neurol Neurochir Pol 2004; 38: 533-537.

13. Litwin T., Kobayashi A., Skowrońska M. i wsp. Thrombolysis in acute ischaemic stroke within 3 hours of symptom onset: a report of the first 100 cases. Neurol Neurochir Pol 2008; 42: 1-5.

14. Bradac G.B., Bergui M., Stura G. i wsp. Periprocedural morbidity and mortality by endovascular treatment of cerebral aneurysms with GDC: a retrospective 12-year experience of a single center. Neurosurg Rev 2007; 30: 117-125.

15. Dowżenko A., Czepiel W., Richter P. i wsp. Endovascular treatment of intracranial aneurysms with remodelling using Leo + stents. Neurol Neurochir Pol 2009; 43: 134-139.

16. Mariak Z., Krejza J., Swiercz M. i wsp. Accuracy of transcranial color Doppler ultrasonography in the diagnosis of middle cerebral artery spasm determined by receiver operating characteristic analysis. $J$ Neurosurg 2002; 96: 323-330.

17. Krejza J., Kochanowicz J., Mariak Z. i wsp. Middle cerebral artery spasm after subarachnoid hemorrhage: detection with transcranial color-coded duplex US. Radiology 2005; 236: 621-629. 